REsumo
A psicanálise contribuiu para
que as crianças deixassem de ser
tomadas como ingênuas e docil-
mente educáveis quando lhes
atribuiu um saber, as teorias
sexuais. Assim demonstrou a
possibilidade de elas formularem
os modos como se procedem as
relações afetivas, sexuais e de
poder entre as pessoas das quais
depende. Na atualidade, a su-
posição de saber às crianças
toma outras conotações quanto
ao lugar politico-libidinal a elas
reservado e abre a dimensão do
gozo sem limites em seu trato
no que concerne aos abusos e às
explorações. Discutiremos acer-
ca do lugar atribuido à criança
na família, na midia e na ciên-
cia.
Descritores: criança; consti-
tuição subjetiva; família; con-
temporaneidade; psicanálise;
saber.

\section{A CRIANÇA NA CONTEMPORANEIDADE: ENTRE SABER E GOZO}

\author{
Miriam Debieux Rosa \\ Cristine Lacet
}

\section{Introdução}

A psicanálise contribuiu para que as crianças deixassem de ser tidas como ingênuas e docilmente educáveis quando se lhes atribuiu um saber, especialmente aquele das teorias sexuais, ou seja, foram-lhe atribuídas possibilidades de conceber de que modo se procedem as relações afetivas, sexuais e de poder entre as pessoas das quais elas dependem. $\mathrm{Na}$ atualidade, a suposição de saber às crian-

Professora do Programa de Psicologia Clínica do Instituto de Psicologia da Universidade de São Paulo e do Programa de PósGraduação da Psicologia Social da Pontificia Universidade Católica de São Paulo, São Paulo, SP, Brasil.

- 1 Psicanalista. Doutoranda pelo Departamento de Psicologia Clínica do Instituto de Psicologia da Universidade de São Paulo. Professora do Curso de Psicologia da Universidade Presbiteriana Mackenzie, São Paulo, SP, Brasil. 
ças toma outras conotações quanto ao lugar político-libidinal reservado a elas, que acompanha os passos da biopolítica e abre a dimensão do gozo sem limites no trato com a criança no que concerne aos abusos e às explorações.

Abordaremos alguns pontos da estratégia de destituir o lugar da infância e do infantil, pela via da criança, particularmente no desmonte do seu lugar como falo e consequente desmonte da constituição da parentalidade, para sua substituição pela gestão da criança via discurso universitário.

Temos hoje alguns sinais preocupantes no campo social e na clínica psicanalítica em relação ao lugar da criança no discurso parental e no imaginário social e sobre a dimensão dos abusos e maus tratos. Já tivemos na história pregressa o infanticídio como um fenômeno social; tivemos a roda dos expostos para deixar os filhos indesejados aos cuidados de outros.

Hoje nos deparamos com notícias sobre bebês atirados às ruas em sacos de lixos, assim como escutamos na clínica, em vez de mães culpadas por sua impaciência com os filhos, mães que declaram, sem espanto, que querem se livrar deles: "Sei que não é muito cristão, mas não gosto nem quero me ocupar dela", ou "Quero devolver para alguém, não pensei que seria tão difícil - você sabe como fazer?”. São sinais de que não é óbvio que a criança seja tomada como falo, condição do primeiro tempo da estruturação da subjetividade. Não basta ter a criança para que se institua a mãe, a parentalidade. Há processos concomitantes que instituem a parentalidade e possibilitam à criança, além da vida puramente biológica (a vida nua), a vida político-social-libidinal.

Atravessamentos contemporâneos nesse processo nos incitam a escutar com apreensão a tese de Postman (1999), um comunicólogo americano segundo o qual assistimos à progressiva perda do sentimento de infância que foi instituído nas estratégias de familiarização da modernidade. O imaginário social é decisivo para o modo como a criança será tomada na estrutura libidinal dos pais. Entre outros e Outro, cria-se para a criança um lugar de existência que pode indicar sua singularidade ou ser gerador de impasses que promovem as condições do desamparo e violação dos direitos. 


\section{Família e constituição subjetiva}

Nesse contexto de deslocamentos e consequentes reconfigurações familiares, a maternidade e a paternidade são lugares discursivos em que comparecem componentes libidinais, sociais e políticos. Tais lugares são instituídos por uma função simbólica, que transcende os familiares, que toca no real e escreve essa relação. Essa escritura funda como um acontecimento o nascimento de uma criança e tem por efeito a atribuição de lugares discursivos, encarnados por representantes sociais - em geral, os pais que por sua vez garantirão a modalidade de inserção da criança e/ou filho nas malhas discursivas. De outro lado, o nascimento da criança como acontecimento que funda a distribuição de lugares discursivos, é um efeito a posteriori, uma vez que não há anterioridade da função materna e paterna - elas se constituem simultaneamente à instituição do lugar discursivo de filho. A função escreve o real pulsional articulado ao imaginário social e à Lei simbólica que constituem um lugar discursivo para pais e filhos, o que possibilita registrar a criança com um nome.

O nascimento de uma criança é um acontecimento que transcende o público ou o privado, pois tem uma dimensão traumática que toca o real - impossível de significar - e produz efeitos simbólicos e imaginários. Es- 
crever um lugar no discurso para a criança como filho de institui as funções parentais e atribui a ela, além da vida nua (zoé), uma vida apoiada na estrutura sócio-política-libidinal (bios), resultado da transmissão de uma herança simbólica, imaginariamente atada à transmissão da tradição de uma comunidade; na contemporaneidade, vige, pelo contrário, o ideal de uma condição de indivíduo auto-engendrado, sem dívida simbólica à cultura que o responsabilize pelas futuras gerações.

Lacan (1987), em sua definição para o verbete "Família", escrito originalmente para a Encyclopédie française e publicado em 1938, propõe que a família teria a função biológica de garantir a sobrevivência dos mais jovens, mas que sua função essencial seria a de transmissão da cultura.

Assim, a cada nascimento de uma criança são postas em jogo as coordenadas que sustentam o grupo social e possibilita o exercício das funções materna e paterna que se operam a partir dos lugares (materno, paterno, filial) atribuídos ou não aos membros de determinada comunidade. A sua eficácia não é independente das coordenadas desse grupo, uma vez que a família é, ao mesmo tempo, o veículo de transmissão dos sistemas simbólicos dominantes e a expressão, em sua organização, do funcionamento de uma classe social, grupo étnico e religioso em que está inserida. A cena social está presente na base da cena familiar, encarregada das opera- ções referentes às funções materna e paterna para a constituição subjetiva (Rosa, 2002). O social, o familiar e seus efeitos articulam-se nos modos como são realizadas as operações necessárias à constituição da subjetividade.

Em Duas notas sobre a criança, Lacan (1981b) aborda a posição que uma criança ocupa junto à família conjugal. A sua função "destaca a irredutibilidade de uma transmissão - que é de uma outra ordem que não a da vida segundo a satisfação das necessidades, mas é de uma constituição subjetiva, implicando a relação com um desejo que não seja anônimo" (p. 373). Essa função tem: a) uma condição: efetivar-se por um interesse particularizado em relação à criança; b) um resultado: a transmissão de um nome que é o vetor de uma encarnação da Lei no desejo.

Esses são pontos fundamentais para a questão tratada nesse texto, uma vez que situam a criança na articulação ao modo de gozo e desejo na família e enfatizam a diferença entre gerações como condição da transmissão de um desejo não anônimo.

\section{Família e contemporaneidade}

Bernardino e Kupfer (2008), referindo-se às transformações sofridas pela família, apontam para a mudança de um modelo que vigorava até o 
século passado, no qual a criança permanecia no ambiente familiar até sua entrada na pré-escola, por volta dos dois, três anos, para sua entrada mais precoce no ambiente social. Relatam que nessa passagem a família como lugar de segurança e referência para a criança é substituída precocemente por um ambiente social e comunitário com suas respectivas leis, em que é introduzida por pessoas que não lhe são familiares, numa transmissão, via de regra, técnica e anônima.

Kehl (2001) referindo-se também à função de transmissão da família, considera que a patologia da família atual não se refere às novas configurações de parentesco, mas à dívida das famílias que se representam como desestruturadas em relação à família nuclear do passado, e referidos a esse ideal os pais hoje apresentam dificuldade em sustentar seu lugar de autoridade e responsabilidade diante dos filhos. Relatam que a mesma cultura moderna que prega que se exerça a função de parentalidade de maneira diferente de nossos antepassados, também apregoa o ideal perdido da família do passado, gerando um sentimento de insuficiência em relação a esse modelo ideal de família. Nesse sentido, a sustentação simbólica transmitida pela família perderia a consistência dada pela tradição; o que esta diz ser pai e mãe não corresponde à experiência do exercício da parentalidade hoje.

Os adultos buscam resgatar o narcisismo perdido através dos filhos, sendo esses últimos considerados como esperança de imortalidade e perfeição numa cultura do narcisismo e individualismo. O risco e o erro na criação dos filhos, que seriam inerentes ao exercício da paternidade, do sujeito que se autoriza numa função e nela se arrisca, tentam ser minimizados e evitados e poucos são aqueles que sustentam o ato necessário para inscrever o filho na cultura como sujeito barrado em seu gozo.

Quando consideramos as modificações das relações entre real, simbólico e imaginário da infância na contemporaneidade, segundo Jerusalinsky (2008), podemos pensar que o que tem se modificado é a premência de que a criança desenvolva sua capacidade simbóli$\mathrm{ca}$, que aprenda, que faça esportes, que fale línguas, que seja independente, que se envolva com uma vida coletiva, etc. O imaginário já lhe vem prêt-à-porter, através de videogames, brinquedos eletrônicos cheios de funções e objetos industrializados, que abrem pouco espaço para que ela crie o seu próprio mundo de fantasia. $\mathrm{O}$ real do corpo da criança continua o mesmo, mas ela é demandada 
a acelerar seu ingresso no universo adulto em suas habilidades, conhecimentos e sexualidade, e sua natural insuficiência frente ao ideal torna-se ainda mais inflacionada e difícil de suportar.

\section{A criança entre o saber e o gozo: os discursos no campo da família, do direito, da ciência e da mídia}

Vivemos atualmente uma decadência de valores da cultura burguesa, sem ideais muito claros. Nesse cenário, os filhos passam a ter o papel de ideal na cultura, funcionando como espelhos narcísicos para os pais, que os criam muitas vezes como uma espécie de seres sem falta - ocupando então um certo lugar de gozo.

Apesar dessa tentativa de obturar a falta, esta comparece como malestar nos diversos sintomas apresentados na infância, no campo da parentalidade e no campo social. "Passa a ter importância crucial o tipo de relação que esses pais têm com a falta, com a castração, para que possam sustentar, à revelia do movimento cultural atual, a questão dos limites e das leis organizadoras. Essa falta de consonância entre o familiar e o social cria uma defasagem geradora de angústia - para os filhos, que estão diante da dupla mensagem, que 
ao mesmo tempo transmite a falta e a renega; para os pais, que estão sozinhos no exercício de sua função" (Bernardino \& Kupfer, 2008, p. 674).

As crianças são convocadas a se posicionar, de modo não apenas a permitir o resgate do narcisismo dos pais (Freud, 1914), processo estruturante e identificatório para ela, mas se tornam o meio através do qual o Outro social concede o gozo a toda família. Opera-se aqui uma inversão: ao invés de transmitir para o filho a falta, o encontro faltoso com o objeto, os pais lhe dirigem a demanda de preenchimento totalizante da falta, impelindo-a na direção do Outro social.

E em relação ao Outro social a criança estaria ocupando um lugar anônimo, distinto da posição fálica que deveria ocupar em relação aos pais, em que teria um lugar personalizado atrelado ao desejo destes últimos. Nesse sentido, ao invés de os pais transmitirem para os filhos os limites do gozo, são estes que lhes apresentam as infinitas possibilidades de gozo atreladas aos objetos do campo social. "Trata-se de satisfazer a este grande campo social, externo, anônimo e globalizante, que tem o seguinte imperativo categórico: consuma, encha-se de objetos, seja feliz, seja eficiente, goze" (Bernardino \& Kupfer, 2008, p. 674)

Vale aqui uma pequena discussão acerca dos efeitos da mídia e da publicidade sobre crianças submetidas a esse imperativo de gozo. 
Baitello Junior (2009) ao discutir a mídia e a sedação das imagens, define a mídia terciária como os meios de comunicação que funcionam com aparelhos tanto do lado do emissor quanto do lado do receptor, aí incluídos a telefonia, a televisão, o cinema, a indústria fonovideográfica, a internet, etc.

Interessa-nos ressaltar algumas características desse tipo de mídia: graças aos sistemas de eletrificação, às redes de cabeamento e a transmissão por ondas, puderam ser desenvolvidos os grandes sistemas de comunicação terciária que se caracterizam pela relativização e mesmo anulação do espaço. Quando enviamos uma mensagem via internet para o Japão ela chega agora, zera-se o espaço. Por outro lado, a mídia terciária provocou uma aceleração do tempo, e a televisão e a internet com a exibição avassaladora de imagens são exemplos categóricos dessa aceleração.

O discurso infantil é atravessado atualmente por novas tecnologias e redes de informática, crianças e adolescentes frequentam lan houses, onde jogam em rede em ambientes acelerados de luz artificial, focadas em sequências frenéticas de imagens. No jogo, só importa seu efeito: vencer, dominar o outro, destruir e aumentar de nível. As imagens tendem a estreitar o campo do sentido; ao invés de serem dotadas de um caráter polissêmico, que implica criação do novo, levam à "cegueira e surdez", que impedem a criação simbólica.

Observa-se nas crianças uma grande dificuldade de fantasiar em função da dificuldade de simbolizar, mesmo crianças inteligentes costumam dizer "nada me ocorre", "não sei', "não entendo", "não sei o que fazer"; são falas e pensamentos vazios de significação. A linguagem visual ocupa cada vez mais espaço, em detrimento da riqueza verbal, corporal, gestual e escrita. Há uma sobreposição do gozo da imagem, sobre o gozo corporal, criativo e gestual; a alienação pela imagem leva à reprodução do mesmo.

O modo de funcionamento próprio das imagens, segundo Kehl (2009) dispensa o pensamento e produz efeito semelhante no sujeito a elas exposto; a imagem funciona como se fosse um microfragmento de gozo que o espectador obtém e a cada fragmento de gozo o pensamento cessa porque é movido pelo desejo e estaria, portanto, sempre em busca do objeto perdido, como em uma tentativa de reconstituir pela via simbólica um substitutivo para esse objeto.

Não precisamos pensar frente ao fluxo contínuo de imagens a que estamos submetidos hoje em dia. Essas imagens nos fornecem 
puro gozo e quanto mais esse fluxo de imagem está presente em nossa vida real e psíquica, menos somos convocados a pensar. Estamos diante de um "imaginário como o lugar desse Outro sem falta - e a publicidade, por exemplo, é uma das vozes desse Outro que sabe sobre nosso desejo e nos oferece a oportunidade de obturar a falta - faz com que o objeto causa do desejo seja intolerável .... O campo de circulação de mercadorias passa a ser imaginariamente o lugar do objeto $a$, e a demanda ocupa o lugar do desejo. Só que a demanda é imperativa, o desejo não" (Kehl, 2009, p.55).

A falta de objeto é tratada aqui na dialética da frustração, como a falta imaginária de um objeto real, como conceitualiza Lacan (1995) em O seminário, livro 4. Estamos no campo da reivindicação, "a frustração é por si mesma o domínio das exigências desenfreadas e sem lei" (Lacan, 1995, p. 36).

Hoje é comum em nossa clínica pais que chegam sentindo-se desautorizados no exercício de suas funções, com dificuldades em estabelecer limites para os filhos, alegando que não conseguem se impor, pois o filho não aceita suas ordens, etc., e que buscam em outros saberes, como os da Medicina ou da Psicologia, respostas sobre como desempenhar seu papel. Trata-se de uma desresponsabilização quanto à função de transmissão de lei que funda justamente os lugares paternos. Não se trata de uma fal- ta de responsabilidade no sentido de cuidar da criança, de preocupar-se com ela, mas o efeito é de abandono de responsabilidade e autoridade.

A autoridade paterna sustenta-se numa posição subjetiva balizada pelo laço simbólico; quando um pai diz que não admite, por exemplo, que o filho lhe fale de maneira desrespeitosa, ele não precisa ameaçar ou explicar a sua posição, ele simplesmente não admite por seu lugar de responsável por aquela criança, e essa seria a função de corte do pai real, tal como foi proposta por Lacan. Nas palavras de Kehl (2001), o pai estaria dizendo: "eu cuido de você, eu escolhi esse encargo e me responsabilizo por ele, eu posso errar aqui e ali, mas eu não vou abandoná-lo" (p. 38). O abandono das crianças "mimadas" da atualidade seria o abandono moral de um adulto que não consegue sustentar sua posição frente à criança, e seria justamente esse ponto que ofereceria a ela parâmetros, inclusive éticos, para se constituir como sujeito.

Essa questão pode ser retomada em outras considerações sobre as funções parentais e o discurso da ciência: consideramos que como efeito do declínio da imago paterna, a intervenção dos discursos científicos, jurídicos e pedagógicos na família e sua tentativa de substituir o pai produzem filiações nem sempre simbólicas. Pode-se dizer da pretensão da Ciência de ordenar os outros discursos e de aparecer como um dos Nomes do Pai. A Ciência gera e modela crian- 
ças, e os efeitos dessa "verdade" contemporânea, se não alertados, podem ser desastrosos para a ética do desejo. A substituição do pai pela ciência remete à transmissão pela via de um desejo anônimo. $\mathrm{O}$ desejo narcísico de ser mãe/pai, o desejo de filho, a vontade de ter a criança já e no modelo desejado, são modalidades que fazem diferença na inscrição do lugar da criança no discurso e no desejo do Outro.

Assim, quando hoje nos deparamos com bebês em sacos de lixos, atirados à rua, não basta ficarmos horrorizados com a mãe ou perguntar-nos sobre sua estrutura clínica; cabe-nos perguntar, isso sim, o que esse fenômeno revela sobre os laços familiares/sociais na contemporaneidade. Registra-se nele a falta da inscrição da criança como filho, como também a não inscrição dos pais nessa posição, a partir da qual uma mulher pode ser mãe e tomar seu filho com objeto amoroso. Porém, além disso, falta a inscrição da criança na ordem humana, fora da qual ela permanece pura vida nua, descartável, matável, como diria Agambem (2002).

Corre-se o risco de um desejo anônimo que obstaculiza a transmissão dos significantes fundamentais (Rosa, 2000), que acompanha os passos da biopolítica em dois tempos:

- o primeiro, atribuindo prevalência ao significante criança (no par criança-adultos) em detrimento do significante filho (no par filho/ pais);

- o segundo refere-se à perda do sentimento de infância, que institui na atualidade a criança como consumidora. A criança atual, se tem maior direito ao gozo e ao saber, sofre o ocultamento do sentido da história e das condições que determinam a subjetividade. Não há diferença entre o que ela consome, veste e usufrui, em relação ao adulto. Torna-se ela mesma objeto de gozo e fascínio coletivo, consumida em seu ser. Abre-se, assim, a dimensão do gozo sem limites no trato com a criança, e fala-se de abuso e exploração de toda ordem, da pedofilia e da redução da idade penal.

Apesar dos discursos orientadores de nosso tempo estarem na direção da anomia, importa "a quem" cabe enunciá-lo, pois faz toda a diferença a sua implicação com a criança. As fantasias presentes no imaginário social podem apresentarse sob o signo do ideal, mas na medida em que são enunciadas a partir da referência à castração parental, são transformadas em enunciações do desejo do Outro. Essa condição não ocorre quando o que predomina é o discurso social em detrimento do familiar. Nessas situações, constata-se a prevalência do discurso adulto-criança e o apagamento do discurso familiar, seja em razão de condições sociais, seja por impossibilidades do desejo. Para esse par, o enunciado é diluído em vários "outros", encarnados aleatoriamente por agentes soci- 
ais descomprometidos. A eles é oferecido apenas o discurso sobre a criança; uma criança que não lhes diz respeito, que não é filho. Esse discurso, carregado de expectativas culturais, desqualifica a criança e a legitimidade de seu discurso e de seus atos.

Tomemos do campo jurídico um exemplo: nesse campo há uma preocupação em proteger as crianças vítimas de abusos e maus tratos do próprio processo jurídico que pode também traumatizá-la com seus procedimentos. Propõe-se o depoimento sem dano: trata-se de um procedimento em que a criança não é exposta a interrogatórios ou tribunais mas relata em sala privada, com alguém com quem estabelece relação de confiança, via verbal ou lúdica, os acontecimentos. Este depoimento é gravado ou assistido em sala de espelho e vai possibilitar a produção de prova necessária para o processo e proteção da criança do agressor familiar. Tudo certo - mas, vejam só -, sem saber a consequência do seu discurso - prova, ela fala em confiança. Ela sabe (os fatos), mas é mantida na ignorância dos poderes em jogo. Mais do que tudo não é a criança que sabe, mas ela é sabida pelo outro - ela é sabida pelo outro, objetalizada ou desmembrada, como diria Lacan, no discurso universitário em nome de suposta proteção à sua ingenuidade que os abusos já dilaceraram.

Estes impasses têm desdobramentos fundamentais. Retomemos as hipóteses de Postman (1999) sobre a 
perda do sentimento de infância; as considerações de Lacan (1981a) sobre a criança generalizada, ou seja, sobre a predominância na atualidade da ignorância, própria do narcisismo, que obtura a dimensão do desconhecimento fundamental para instauração do enigma da existência - tais considerações alertam que supor que se saiba tudo sobre um sujeito, tomado como um corpo desmembrável, abre para a segregação.

Retornemos ainda à análise de Agambem (2004) sobre a importância do infantil para a relativização da verdade e como base de sustentação da experiência e da instituição da historicidade. A revigoração da parentalidade, independente da modalidade de configuração familiar que se apresente, é ponto de resistência micropolítico ao avanço de tais processos.

Estas considerações nos demonstram que a reflexão e o debate sobre a criança, além de tratar das condições de possibilidade de instituir-se junto a crianças e adolescentes a naturalização da arbitrariedade, em vez de cuidados e educação, remete à dimensão da ética no contemporâneo. Por isso, consideramos que a psicanálise com crianças, seja na clínica, na educação ou na política, deve levar em conta as modalidades de discurso que possibilitam a parentalidade e que atribuem, ou não, lugar de sujeito à criança. Para isto, deve-se verificar os enunciados sociais, jurídicos e desordens genealógicas (como suporte identificatório), o romance familiar e o discurso da criança e de seus pais.

THE CHILD IN CONTEMPORARY SOCIETY: BETWEEN KNOWLEDGE AND JOUISSANCE

\begin{abstract}
Psychoanalysis has contributed for children no longer to be taken as naïve and easily educable when it gave them a knowing, the sexual theories. Thus, it has demonstrated that they can formulate the ways in which the emotional, sexual and power relationships evolve among the people on whom they depend. At present, the assumption that children have a knowing takes other connotations as to the political-libidinal place reserved for them, which opens the dimension of limitless jouissance in dealing with them regarding abuse and explorations. We will discuss about the place given to the child in the family, media and science.
\end{abstract}

Index terms: child; subjective constitution; family; contemporaneity; psychoanalysis; knowing. 


\section{RESUMEN}

El psicoanálisis contribuyó para que los niños dejasen de ser considerados como ingenuos y dócilmente educados cuando se les atribuyó un conocimiento, sobre todo las teorias sexuales. Así han demostrado sus posibilidades de formular las formas de cómo son las relaciones afectivas, sexuales, y de poder entre las personas de que dependen. En la actualidad, la suposición de saber a los niños tiene otras conotaciones en relación al sitio político-libidinal que se les ha reservado y abre la dimensión del goce sin limites en el trato con el niño sobre los abusos y explotaciones. Discutiremos acerca del lugar otorgado al niño en la familia, en los medios de comunicación y en la ciencia.

Palabras claves: niño; la constitución subjetiva; familia; contemporaneidad; psicoanálisis.

\section{REFERÊNCIAS}

Agamben, G. (2002). Homo sacer. O poder soberano e a vida nua I. Belo Horizonte: Ed. UFMG.

Agambem, G. (2004). Infância e bistória: ensaio sobre a destruição da experiência. Buenos Aires: AH Adriana Hidalgo Ed.

Baitello Jr, N. (2009). A mídia e a sedação das imagens. In M. C. M. Comparato \& D. S. F Monteiro, A criança na contemporaneidade e a psicanálise: mentes e mídia. (Vol. 2, pp.25-33), São Paulo: Casa do Psicólogo.

Bernardino, L. M. F., \& Kupfer, M. C. M. (2008, setembro). A criança como mestre do gozo da família atual: desdobramentos da "pesquisa de indicadores clínicos de risco para o desenvolvimento infantil". Revista Mal-estar e Subjetividade, 8(3), 661-680.

Freud, S. (1972). Sobre o narcisismo: uma introdução. In S. Freud, Edição standard brasileira das obras psicológicas completas de Sigmund Frend (J. Salomão, trad., Vol. 14, pp. 89-119). Rio de Janeiro: Imago. (trabalho original publicado em 1914).

Jerusalinsky, A. (2008, jan./jun). Crianças ocupadíssimas, pais angustiadíssimos? Revista da Associação Psicanalitica de Porto Alegre, 34, 175-181.

Kehl, M. R. (2001). Lugares do feminino e do masculino na família. In M. C. M. Comparato \& D. S. F. Monteiro (Orgs.), A criança na contemporaneidade e a psicanálise: família e sociedade (Vol. 1, pp. 29-38). São Paulo: Casa do Psicólogo.

Kehl, M. R. (2009). A violência do imaginário. In M. C. M Comparato \& D. S. F. Monteiro. A criança na contemporaneidade e a psicanálise: mentes e mídia (Vol. 2). São Paulo: Casa do Psicólogo.

Lacan, J. (1987). Os complexos familiares. Rio de Janeiro: Zahar. (Trabalho original publicado em 1938)

Lacan, J. (1981a). Alocução sobre as psicoses da criança. In J. Lacan, Outros escritos (pp.359-368). Rio de Janeiro: Jorge Zahar Editor. (trabalho original publicado em 1967) 
Lacan, J. (1981b). Nota sobre a criança. In J. Lacan, Outros escritos (pp.369-370). Rio de Janeiro: Jorge Zahar Editor. (trabalho original publicado em 1969)

Lacan, J. (1995). O seminário, livro 4: a relação de objeto, 1956-1957 (D. D. Estrada, trad.). Rio de Janeiro: Jorge Zahar Editor.

Postman, N. (1999). O desaparecimento da infância. Rio de Janeiro: Ed. Graphia.

Rosa, M. D. (2000). Histórias que não se contam: o não dito na psicanálise com crianças e adolescentes. São Paulo: Editora Cabral.

Rosa, M. D. (2002). Adolescência: da cena familiar à cena social. Psicologia USP, São Paulo. 13(2), 227-242.

debieux@terra.com.br Al. Joaquim Eugênio de Lima 1041/72. 01403-000 - São Paulo - SP - Brasil.

crislacet@yahoo.com.br Praça Japubá, 35/74 B. 05453-060 - São Paulo - SP - Brasil.

Recebido em agosto/2011. Aceito em novembro/2011. 